\title{
Assessment of the relative systemic potency of inhaled fluticasone and budesonide
}

\author{
M Boorsma*, N. Andersson**, P. Larsson**, A. Ullman**
}

Assessment of the relative systemic potency of inhaled fluticasone and budesonide. M Boorsma, N. Andersson, P. Larsson, A. Ullman. (C)RS Journals Ltd 1996.

ABSTRACT: Studies using dry powder devices have suggested that fluticasone propionate (FP) has a greater systemic effect than budesonide (BUD). The aim of the present study was to investigate and compare the relative systemic potency of FP and BUD from their respective pressurized metered-dose inhalers (pMDIs).

A placebo-controlled, open, randomized, cross-over study was conducted in 21 healthy male volunteers. Placebo, BUD (200, 400 and 1,000 $\mu \mathrm{g}$ b.i.d.) and FP (200, 375 and $1,000 \mu \mathrm{g}$ b.i.d.) were inhaled for 4 days, with a wash-out period of at least 3 days between treatments. Blood samples for cortisol analysis were drawn during the last $24 \mathrm{~h}$ of each treatment period.

Cortisol levels, measured as $24 \mathrm{~h}$ pooled plasma cortisol, were statistically significantly lower $(p=0.0001)$ for all dose levels during FP pMDI treatment $(21,39$ and $84 \%$ suppression from placebo) than during BUD pMDI treatment $(1,3$ and 27\% suppression from placebo). The relative systemic potency FP:BUD was 3.7:1 (95\% confidence interval $(95 \%$ CI) $2.9-4.8)$ ). The relative systemic potency based on the single 08:00 $\mathrm{h}$ samples was 5.2:1 (95\% CI 3.0-9.3).

In conclusion, in healthy male volunteers using pressurized metered-dose inhalers, fluticasone propionate was shown to have a stronger systemic effect than budesonide.

Eur Respir J., 1996, 9, 1427-1432.

\author{
*Astra Pharmaceutica BV, Zoetermeer, \\ The Netherlands. **Astra Draco AB, Lund, \\ Sweden. \\ Correspondence: M Boorsma \\ Astra Pharmaceutica BV \\ P.O. Box 599 \\ NL-2700 AN Zoetermeer \\ The Netherlands \\ Keywords: Budesonide \\ cortisol suppressive effect \\ fluticasone propionate \\ relative systemic potency
}

Received: December 281995 Accepted after revision April 101996
It is now well-accepted that inhaled glucocorticosteroid (GCS) therapy should be introduced as soon as asthma patients regularly use $\beta_{2}$-agonists $[1,2]$. GCS therapy is being introduced successfully with increasing frequency in mild symptomatic asthma patients and also at an earlier stage after diagnosis [3, 4]. Since GCS therapy is chronic, this increased exposure in patients with mild to moderate asthma puts demands on the safety profile of GCS [5, 6], as determined by the therapeutic efficacy and the systemic activity.

Fluticasone propionate (FP) is a recently introduced, highly potent GCS [7], and is available in aerosol (pressurized metered-dose inhaler (pMDI)) and dry powder (Diskhaler $\left.{ }^{\circledR},(\mathrm{DH})\right)$ formulations. In patient population studies with mild and moderate $[8,9]$ or severe $[10,11]$ asthmatics, it has been suggested that FP may be clinically twice as effective as beclomethasone dipropionate (BDP pMDI [10]) and budesonide (BUD pMDI [8, 11]; Turbuhaler®, (TBH) [9]). Similar differences were found by ENGLISH et al. [12] in the human vasoconstrictor test, an assay used to determine the rank order of steroid activity. ANDERSSOn et al. [13], however, demonstrated equipotency of FP and BUD using a similar methodology.

FP pMDI has also been reported to have systemic activity similar to or less than BDP pMDI, as reflected by morning cortisol samples taken during clinical use in an out-patient setting [14, 15]. However, three recent controlled studies have suggested that FP may have a greater systemic activity than BUD (DH vs TBH [16, 17],
pMDIs [18]). In order to make a correct assessment of the relative systemic activity on a milligram for milligram nominal dose basis, dose-responses of both drugs should be established, using sensitive parameters to determine systemic activity.

Due to the large inter- and intrasubject variability in a single plasma cortisol sample, single morning sampling is considered less sensitive than determining the cortisol production over a day. This can be accomplished by taking multiple blood samples over, for example, a 20$24 \mathrm{~h}$ period or by measuring cortisol excretion in urine.

The aim of the present study was to determine the relative systemic potency of FP pMDI and BUD pMDI on a milligram for milligram nominal dose basis in healthy volunteers, under standardized conditions.

Subjects and methods

\section{Ethical considerations}

The study was conducted according to Good Clinical Practice at Pharma Bio Research, Zuidlaren, The Netherlands, and was approved by an independent Medical Ethics Committee. All volunteers gave written informed consent following a verbal and written explanation of the study. 


\section{Subjects}

Twenty one healthy male subjects were included in this study. Their ages ranged from 19-28 (mean 24) yrs. All had a body weight within $15 \%$ of normal (1983 Metropolitan) body weight range relative to height and frame size. One week prior to, and just after, the study, the subjects underwent a physical examination. Vital signs and electro cardiographic activity (ECG) were recorded and routine haematological and biochemical tests were performed at these examinations.

\section{Study design}

The study was of a multiple-dose, open, randomized, seven period, cross-over design. The following treatments were administered in random order (in blocks of three subjects), twice daily at 10:00 and 22:00 hrs for 4 days: Placebo, four puffs; BUD $200 \mu \mathrm{g}$, four puffs of $50 \mu \mathrm{g}$; BUD $400 \mu \mathrm{g}$, four puffs of $100 \mu \mathrm{g}$; BUD $1,000 \mu \mathrm{g}$, five puffs of $200 \mu \mathrm{g}$; FP $200 \mu \mathrm{g}$, four puffs of $50 \mu \mathrm{g}$; FP $375 \mu \mathrm{g}$, three puffs of $125 \mu \mathrm{g}$; FP $1,000 \mu \mathrm{g}$, four puffs of $250 \mu \mathrm{g}$. Placebo and budesonide canisters were manufactured by Astra, Sweden; and FP canisters by Glaxo, UK. A wash-out period of at least 3 days separated each of the treatment periods. No large volume spacers were used. The canisters were shaken before each dose and the puffs were inhaled with intervals of $30 \mathrm{~s}$. The subjects were trained prior to each treatment period in an optimal inhalation technique using placebo inhalers connected to a modified Vitalograph Compact (Vitalograph Ltd, Buckingham, UK). After slow, complete exhalation, full inspiration was achieved at an inspiratory flow of approximately $0.5 \mathrm{~L} \cdot \mathrm{s}^{-1}$. The metered-dose inhaler was actuated after approximately $0.5 \mathrm{~s}$ and the subjects were asked to hold their breath for $10 \mathrm{~s}$ following each inhalation. After completing the last inhalation, the subjects rinsed their mouth with $200 \mathrm{~mL}$ water and spat the water out to minimize the swallowed portion of the steroids.

For the first six doses of each treatment period, the subjects were ambulant but reported to the clinical research facility for study drug administration. For the last two doses, the subjects were admitted to the clinical research facility and remained there for $36 \mathrm{~h}$. They refrained from exercise and stress and their diets were standardized. Inhalation and blood sampling were always performed with the subjects in the same sequence.

During the last $24 \mathrm{~h}$ of each treatment period, repeated blood sampling ( $3 \mathrm{~mL}$ per sample) was performed using an indwelling catheter. Samples were collected every other hour from 22:00 h (immediately prior to dosing) up to 22:00 $\mathrm{h}$ the next day. Additional samples were drawn at 07:00 and 09:00 h. The sample at 10:00 h was taken just before the last dose. The subjects were not allowed to lie down during the first $10 \mathrm{~min}$ after inhalation and were instructed to stay in bed from 24:00 to 07:30 h. Blood samples were immediately cooled at $0^{\circ} \mathrm{C}$ and centrifuged within $30 \mathrm{~min}$. Plasma was immediately frozen at $-20^{\circ} \mathrm{C}$ until analysed.

\section{Plasma cortisol analysis}

The plasma cortisol content was determined by radioimmunoassay (RIA) (DPC, Apeldoorn, The Netherlands).
Initially, the samples taken over a $24 \mathrm{~h}$ period were pooled per subject for each treatment. Pooling was performed with equal volumes of plasma except for halved volumes for the 22:00, 07:00, 08.00, 09:00, 10:00 and 22:00 $\mathrm{h}$ samples and the average $24 \mathrm{~h}$ cortisol level determined. In addition, 08:00 $\mathrm{h}$ plasma cortisol was determined for each subject and treatment.

At a later stage, all individual samples were analysed and plasma cortisol profiles were established. The average cortisol concentration over $24 \mathrm{~h}$ was then calculated from the 15 samples per subject and treatment using the trapezoidal method.

As an additional exploratory analysis, plasma cortisol samples were pooled from all subjects for each timepoint per treatment in order to examine the pooled plasma cortisol profile.

One RIA batch was used for all analyses. The lower limit of detection for cortisol with this kit is $11 \mathrm{nmol} \cdot \mathrm{L}^{-1}$. The coefficient of variation of the assay method was $4 \%$ at a concentration of $548 \mathrm{nmol} \cdot \mathrm{L}^{-1}$ and $7 \%$ at $69 \mathrm{nmol} \cdot \mathrm{L}^{-1}$. Normal morning cortisol concentrations in healthy subjects are $\geq 170 \mathrm{nmol} \cdot \mathrm{L}^{-1}$.

\section{Statistical analysis}

The number of subjects to be used in this study was estimated using historical $20 \mathrm{~h}$ mean plasma cortisol data [16]. With 21 subjects, a difference in plasma cortisol suppression from placebo of $13 \%$ between FP and BUD could be detected, with $80 \%$ power at the 0.05 level. The primary variables were the cortisol level in the $24 \mathrm{~h}$ pooled samples and in the 08:00 h samples. The results were analysed by analysis of variance (ANOVA) with subject, treatment and period as factors. Cortisol values after GCS treatment were compared with those after placebo and between FP and BUD for each of the three dose levels. Two-sided p-values below 0.05 were regarded as statistically significant. An additional ANOVA was performed with previous treatments as a factor to investigate a possible carry-over effect. Cortisol values in the pooled sample were compared with the calculated average level by correlation characteristics.

Cortisol levels are described both as geometric and arithmetic mean values. The percentage reduction was calculated for each individual subject relative to the value after placebo and expressed as arithmetic mean values. Cortisol values below the lower limit of detection $\left(11 \mathrm{nmol} \cdot \mathrm{L}^{-1}\right)$ were arbitrarily set at $5.5 \mathrm{nmol} \cdot \mathrm{L}^{-1}$ for statistical analyses. The relative systemic activity was calculated by fitting a nonlinear curve model for the $24 \mathrm{~h}$ pooled and the 08:00 h values. Two parallel sigmoidal curves were fitted to the individual data using the following equation:

$$
\text { Response }=E_{\max } \quad 1-\left(\frac{1}{1+e^{-b\left(-a_{i}+\ln (\text { dose })\right)}}\right)
$$

where response is the cortisol value as percentage of the value after placebo in the $24 \mathrm{~h}$ pooled and the 08:00 $\mathrm{h}$ sample, with $i=1$ for BUD and 2 for FP. A nonlinear mixed effect model approach was used, which means that maximum effect ( $E \max ), \mathrm{b}, a_{1}$ and $a_{2}$ were assumed to be individual parameters, normally distributed in the population. A numerical algorithm was used to estimate the mean parameters and the relative systemic potency was estimated as $\exp \left(a_{1}-a_{2}\right)$ 


\section{Results}

All 21 volunteers completed the study as planned, but one subject needed a 2 week wash-out after his second treatment period because of pharyngitis. The routine tests at entry and after the study revealed no clinically significant abnormalities.

\section{Period and carry-over effects}

For the $24 \mathrm{~h}$ pooled sample, no statistically significant period or carry-over effects were detected. For the 08:00 h sample, no statistically significant carry-over effect was detected, but there was a statistically significant period effect, with the lowest values observed during period 3 and highest values during period 2. However, since the study was completely balanced with respect to periods, a period effect will not affect the differences between treatments.

\section{4 h pooled plasma cortisol sample}

The mean $24 \mathrm{~h}$ pooled plasma cortisol samples (Cav, pooled) were compared. The difference between FP pMDI and BUD pMDI in the measured cortisol levels was statistically significant for all three dose levels $(\mathrm{p}=0.0001)$. Mean plasma cortisol values are reported in table 1 , and the mean reduction in plasma cortisol as a percentage of the value after placebo treatment is shown in figure 1. For FP, a dose-dependent reduction in the plasma cortisol values was observed, increasing from a mean value of $21 \%$ after FP $200 \mu \mathrm{g}$ b.i.d. to $39 \%$ after FP $400 \mu \mathrm{g}$ b.i.d. and $84 \%$ after FP 1,000 $\mu$ g. b.i.d. The cortisol suppression after FP, as compared with placebo, was statistically significant $(\mathrm{p}=0.0001)$ for all three doses. The low and middle doses of BUD did not cause a statistically significant cortisol suppression (1.2 and 3.4\%, respectively), but BUD 1,000 $\mu \mathrm{g}$ b.i.d. resulted in a mean cortisol suppression of $27 \%$ relative to the placebo treatment $(\mathrm{p}=0.0001)$.

Table 1. - Cortisol levels after treatment for 4 days with placebo, fluticasone propionate and budesonide in 21 healthy subjects

\begin{tabular}{lcc}
\hline Treatment & $\begin{array}{c}\text { Cav, pooled } \\
\mathrm{nmol} \cdot \mathrm{L}^{-1}\end{array}$ & $\begin{array}{c}\mathrm{C} 08: 00 \\
\mathrm{nmol} \cdot \mathrm{L}^{-1}\end{array}$ \\
\hline $\begin{array}{l}\text { Placebo } \\
\text { Fluticasone propionate }\end{array}$ & $161 / 164(37)$ & $323 / 334(91)$ \\
$200 \mu \mathrm{g}$ b.i.d. & $123 / 129(42)$ & $247 / 274(120)$ \\
$375 \mu \mathrm{g}$ b.i.d. & $86 / 100(37)$ & $137 / 230(119)$ \\
$1000 \mu \mathrm{g}$ b.i.d. & $15 / 25(27)$ & $14 / 38(65)$ \\
Budesonide & $156 / 160(35)$ & $288 / 309(108)$ \\
$200 \mu \mathrm{g}$ b.i.d. & $151 / 156(35)$ & $295 / 322(109)$ \\
$400 \mu \mathrm{g}$ b.i.d. & $112 / 121(42)$ & $253 / 292(117)$ \\
$1000 \mu \mathrm{g}$ b.i.d. &
\end{tabular}

Values are presented as geometric/arithmetic mean, and SD in parenthesis. Cav, pooled: $24 \mathrm{~h}$ pooled cortisol sample; C08:00h: $08.00 \mathrm{~h}$ plasma cortisol sample.

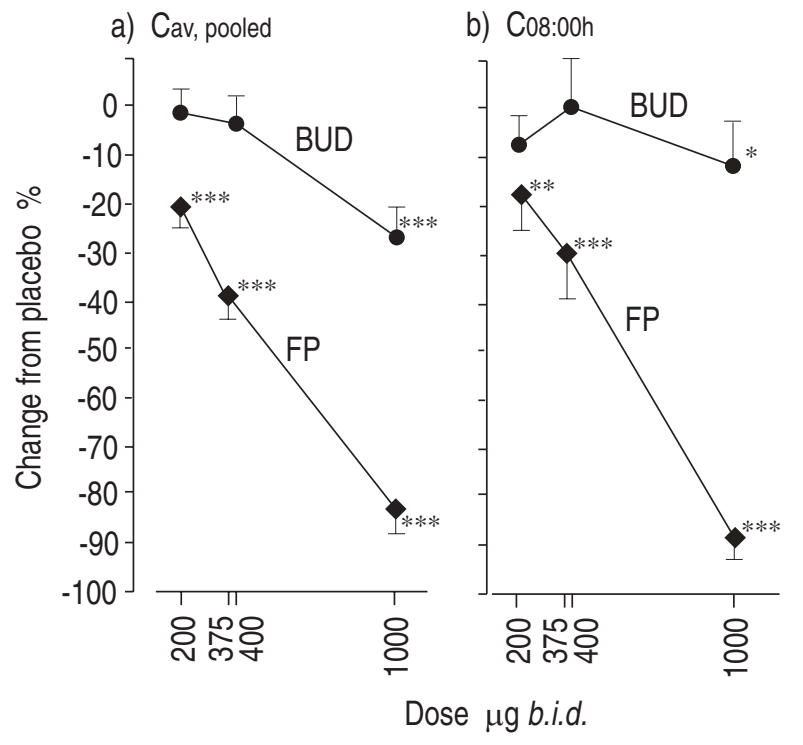

Fig. 1. - Dose response for the percentage change from placebo cortisol levels: a) in the $24 \mathrm{~h}$ pooled sample (Cav, pooled); and b) at 08:00 $\mathrm{h}(\mathrm{C} 08.00 \mathrm{~h})$ as observed on the last day of treatment with inhaled fluticasone propionate (FP) and budesonide (BUD). Values are presented as meantsEM. *: $\mathrm{p}<0.05 ; * *: \mathrm{p}<0.005 ; * * *: \mathrm{p}<0.0001$, compared to placebo.

The individual dose-responses and fitted curves are shown in figure 2 . From the nonlinear curve fitting, the relative systemic potency was estimated to be 3.7 (95\% confidence interval $(95 \% \mathrm{CI}) 2.9-4.8)$, i.e. 3.7 times as much BUD pMDI was required to suppress plasma cortisol to the same extent as did FP pMDI.

In 11 pooled plasma samples, the cortisol level was below the detection limit $\left(<11 \mathrm{nmol} \cdot \mathrm{L}^{-1}\right)$; in 10 subjects during FP 1,000 $\mu \mathrm{g}$ b.i.d. treatment and in one of them also during FP $375 \mu \mathrm{g}$ b.i.d. treatment.

\section{Single morning 08:00 h samples}

The mean 08:00 h plasma cortisol samples $(\mathrm{C} 08: 00 \mathrm{~h})$ were compared. The low and middle BUD dose did not result in statistically significant changes in 08:00 plasma cortisol as compared with placebo $(7.1 \%$ suppression and $0.7 \%$ increase, respectively). The highest dose $(1,000 \mu \mathrm{g}$ b.i.d.) induced a small $(11 \%)$ but statistically significant suppression $(\mathrm{p}<0.05)$ as compared with placebo. In contrast, FP treatment induced a dose-dependent suppression from $18 \%$ at the low dose, $30 \%$ at the middle dose and increasing to $89 \%$ at the highest dose. The suppression from placebo was statistically significant $(\mathrm{p}<0.0005)$ for all three doses. Mean values are shown in figure 1. From the curve-fitting, the relative systemic activity was estimated to be 5.2 (95\% CI 3.0-9.3).

A statistically significant difference was found between the morning cortisol concentrations after FP and BUD at the two highest dose levels $(\mathrm{p}=0.001)$. Individual and geometric mean data are shown in figure 3 . During FP treatment at the highest dose $(1,000 \mu \mathrm{g}$ b.i.d.), only two of the 21 cortisol concentrations were within the normal range. In 16 of the 08:00 h samples, cortisol levels were below the limit of detection: in three samples after FP $375 \mu \mathrm{g}$ b.i.d. and in 13 samples after FP 1,000 $\mu \mathrm{g}$ b.i.d. 
a) Budesonide

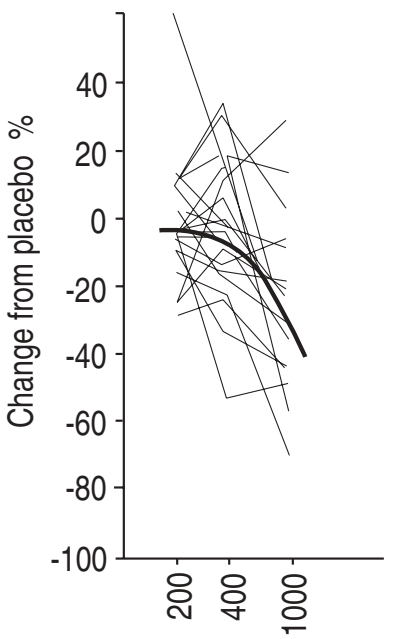

Dose $\mu$ g b.i.d. b) Fluticasone



Dose $\mu$ g b.i.d. c) Mean curves

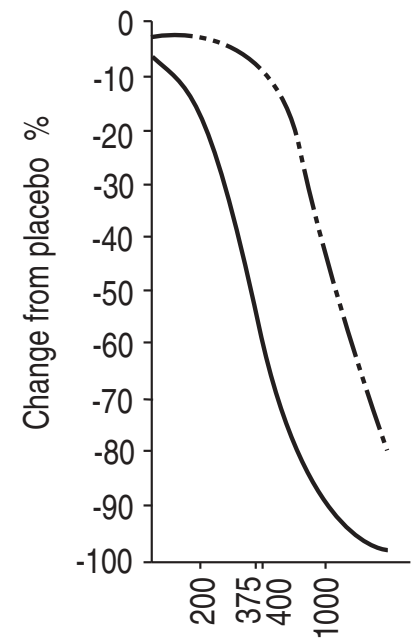

Dose $\mu$ g b.i.d.

Fig. 2. - Individual dose-responses for a) budesonide; and b) fluticasone; and c) fitted mean curves for the $24 \mathrm{~h}$ pooled plasma cortisol values (Cav,pooled), expressed as percentage change from placebo during budesonide and fluticasone treatment. _- _ : fluticasone; —- - - : budesonide.



Fig. 3. - Individual and geometric mean 08:00 h plasma cortisol values as observed on the last day of treatment with placebo, budesonide and fluticasone propionate. The horizontal dotted line indicates the lower limit of normal reference range $\left(170 \mathrm{nmol} \cdot \mathrm{L}^{-1}\right)$.

\section{Plasma cortisol time profile}

The mean cortisol levels, determined from individual time points throughout the $24 \mathrm{~h}$ dosing interval, are shown in figure 4.

As compared with placebo, a lower cortisol curve was obvious for all three FP treatments and for the highest BUD dose. Inspection of individual data (not shown) revealed that in eight cases, all during FP 1,000 $\mu \mathrm{g}$ b.i.d. treatment, cortisol levels were below the level of detection throughout the $24 \mathrm{~h}$ sampling period.

\section{Feasibility of pooling}

There was a close correlation $(r=0.965)$ between the $24 \mathrm{~h}$ mean cortisol level determined from a single pooled sample and the $24 \mathrm{~h}$ mean cortisol level calculated from the 15 separate time-points (147 data points $(21$ subjects

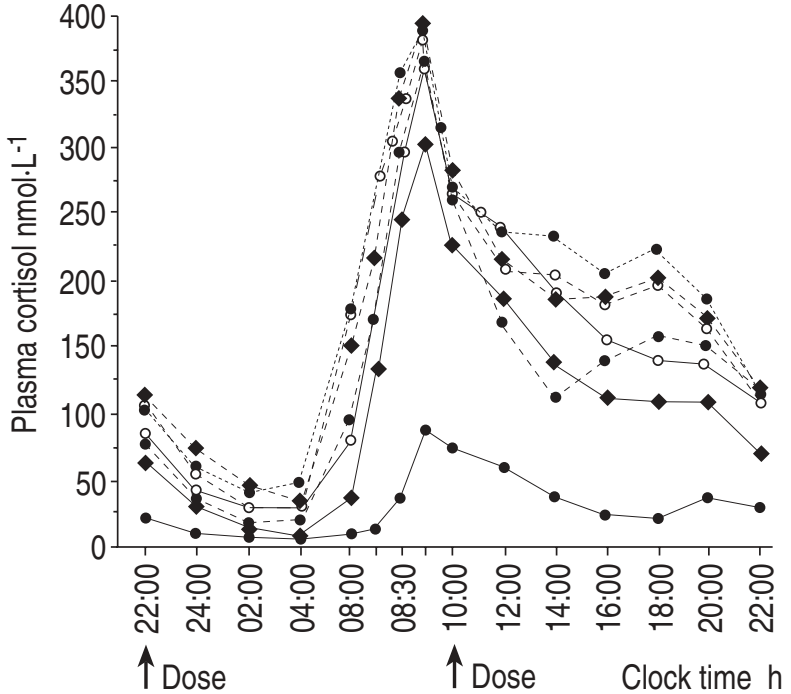

Fig. 4. - Mean plasma cortisol concentration versus time during the last two dosing intervals for fluticasone propionate, budesonide and placebo. Dosing times are indicated by arrows. .......... : placebo; - - - : budesonide $200 \mu \mathrm{g}$ b.i.d.; - - - - : budesonide $400 \mu \mathrm{g}$ b.i.d.; - - - - : budesonide $1000 \mu \mathrm{g}$ b.i.d.; $\longrightarrow-$ : fluticasone $200 \mu \mathrm{g}$ b.i.d.; $\longrightarrow$ : fluticasone $375 \mu \mathrm{g}$ b.i.d.; $\longrightarrow$ : fluticasone $1000 \mu \mathrm{g}$ b.i.d.

$\times 7$ periods)) (fig. 5). Pooling per time-point also yielded very similar data as compared with the mean of the individual samples per time-point (not shown), with a correlation coefficient of 0.997 for the 105 data points (15 time points $\times 7$ periods).

\section{Discussion}

In this study, statistically significant systemic effects of inhaled FP were found, reaching a plasma cortisol suppression, as compared with placebo, of more than $80 \%$ at the highest dose tested. The relative systemic potency of FP pMDI as compared with BUD pMDI was estimated to be 3.7 , based on the $24 \mathrm{~h}$ pooled data, and 


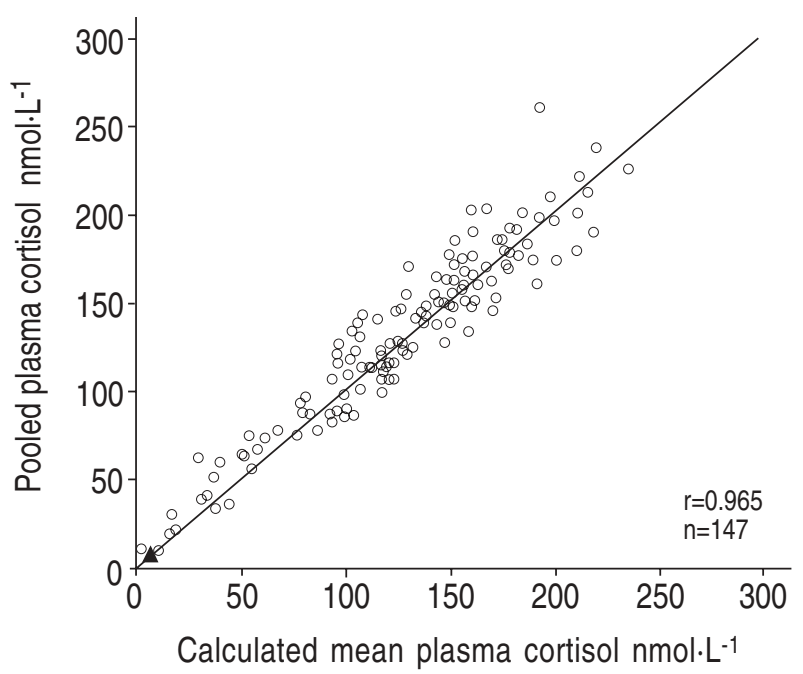

Fig. 5. - Correlation between cortisol levels in the $24 \mathrm{~h}$ pooled plasma samples (Cav, pooled) and the calculated mean (Cav, calculated) $24 \mathrm{~h}$ mean value $(\mathrm{n}=147)$; the line of identity is included. $\mathbf{\Delta}$ : ten identical values.

5.2, based on the 08:00 h samples. Both for the $24 \mathrm{~h}$ pooled plasma data and the 08:00 $\mathrm{h}$ plasma data, the steep part of the dose-response curve appears to have been reached even with the lowest dose of FP pMDI. This is not the case for BUD pMDI.

The main determinant of systemic availability, and thus also of systemic effects, both of FP and BUD is the fraction of the dose absorbed through the lung [19], since no biotransformation of either of these drugs takes place in the lung. Thus, the lung deposition characteristics of the inhaler will play an important role in the degree of systemic activity observed. However, no comparative data on the lung deposition of the two aerosols used in the present study are available. Aerosols from different manufacturers, with different drugs, combinations of freon and surface active agents, may not have the same lung deposition characteristics. Nevertheless, all pMDIs require the same inhalation technique and, in the present study, an optimal inhalation technique was trained and used. The results confirm the suggested stronger systemic effect of FP as compared with BUD seen in previous studies $[16,17]$ using dry powder inhalers.

In many clinical studies, single morning plasma cortisol samples are usually drawn between 08:00 and 10:00 h. In these out-patient clinical studies, an effect on the hypothalamic pituitary-adrenocortical (HPA)-axis of inhaled GCS is difficult to detect, since the exact time of blood sampling (and dosing) is less stringently controlled than in a clinical pharmacological study. In the present study, the $95 \%$ CIs for the relative systemic potency are wider for the single 08:00 $\mathrm{h}$ samples than for the $24 \mathrm{~h}$ pooled data. Thus, even under controlled conditions, with standardized dosing in the evening and rising at 07:30 h, a single morning assessment at 08:00 $\mathrm{h}$ is more variable than an integrated measurement. Using methods of integrated cortisol concentrations, either by multiple and frequent blood sampling, or by determining the $24 \mathrm{~h}$ urinary excretion of cortisol, suppressive effects of GCS are easier to detect, even at low doses of inhaled steroids [20-24].

In most clinical studies with FP, only single morning plasma cortisol concentrations have been reported, with geometric mean values within the normal range $[14,15]$. However, other systemic effects have been observed [22, $23,25,26]$. In a dose-response study, CHERvinsky et al. [22] showed morning cortisol to be unaltered by FP treatment, but adrenocorticotrophic hormone $(\mathrm{ACTH})$ tests and urinary cortisol excretion tests were abnormal in about a quarter of the patients treated with FP $500 \mu \mathrm{g}$ b.i.d.

Three design aspects of the present study require some consideration. Firstly, the study was of an open design. However, the subjects were trained in optimal pMDI inhalation technique and they used the same technique for both drugs. In addition, the primary variable, plasma cortisol, is an objective measurement. Thus, the nonblinding of the study is of little relevance.

Secondly, cross-over studies carry an inherent risk of carry-over effects. No such effects were detected in the analysis of the data. However, due to the design of the study (multiple $24 \mathrm{~h}$ blood sampling and seven way cross-over), it was not feasible to add a baseline $24 \mathrm{~h}$ sampling period at the start of each treatment period (blood volume considerations). Thus, a carry-over effect cannot be categorically excluded. However, if present, a carry-over effect would most likely be associated with the periods after those in which a large cortisol suppression was observed and would lead to an underestimation of the actual differences between treatments.

Thirdly, the use of healthy subjects must be considered. The degree of cortisol suppression seen in this study appears to be greater than that presented in some, but not all, studies in asthmatic patients $[11,14,15,18$, $22,25]$. This may be explained by the use, in this study, of a sensitive measure of HPA-axis, effects i.e. repeated plasma cortisol sampling. However, differences between healthy subjects and asthmatic patients with respect to lung drug deposition and/or sensitivity to GCS cannot be excluded. Nevertheless, any such difference between subject and patient populations is the same for both drugs and cannot explain the differences between drugs seen in this study.

A possible explanation for the observed difference in magnitude of the systemic effect between drugs in the present study might be the difference in pharmacokinetic properties of FP and BUD. Both GCS are reported to have a low bioavailability of the swallowed fraction: $10 \%$ for BUD and $1 \%$ for FP $[7,27]$, whilst the fraction deposited in the lungs will be fully bioavailable, since neither of the two GCS are locally biotransformed. Thus, although the inhaled fraction is smaller than the fraction which is swallowed, it provides the major contribution to the total bioavailability of the inhaled GCS. The terminal half-lives $(t 1 / 2)$ of FP and BUD are known to differ markedly; $t 1 / 2$ for BUD is $2.3 \mathrm{~h}$ [28], whilst $t 1 / 2$ for FP has recently been reported to be $7.8 \mathrm{~h}$ [29]. With a longer $t 1 / 2$, accumulation may occur. Indeed, this has been suggested by data from a previous study [16], in which pronounced cortisol suppression was observed after repeated dosing with FP-DH 1,000 $\mu \mathrm{g}$ b.i.d. as compared with a single dose of $1,000 \mu \mathrm{g}$.

Furthermore, pharmacodynamic differences may play a role. The reported strong binding of FP to the glucocorticosteroid receptor may add to the observed greater systemic activity [7].

Thus, even with a suggested twofold difference in clinical effect using pMDIs [8, 11], the observed fourfold 
stronger systemic effect would give rise to a smaller efficacy/safety ratio for FP pMDI as compared with BUD pMDI.

A secondary aim of the study was to investigate aspects of pooling of plasma samples prior to measuring the cortisol concentrations, instead of firstly performing all the analyses and then calculating their mean value. Differences between the calculated mean and the pooled mean were very small. Thus, using pooled data, the same information on the dose-response relationship was obtained with a 15 fold smaller number of cortisol analyses. By additionally pooling the samples per time-point within each treatment for all subjects, a time profile could be obtained. Though missing an estimate of the interindividual variation, the means of pooled samples per time-point give relevant information about the time course of any effects and were almost identical to the calculated profile values.

In conclusion, in healthy male volunteers, fluticasone propionate pressurized metered-dose inhaler was shown to have a stronger systemic effect than budesonide pressurized metered-dose inhaler.

Acknowledgement: The authors would like to acknowledge the staff of Pharma Bio Research, Zuidlaren, The Netherlands for presenting this study at an international meeting [30].

\section{References}

1. Woodhead M (ed). Guidelines on the management of asthma. Thorax 1993; 48 (Suppl): S1-S24.

2. Barnes PJ. Drug therapy: inhaled glucocorticoids for asthma. N Engl J Med 1995; 332: 868-875.

3. Haahtela T, Järvinen M, Kava T, et al. Comparison of a beta ${ }_{2}$-agonist, terbutaline, with an inhaled corticosteroid, budesonide, in newly detected asthma. N Engl J Med 1991; 325: 388-392.

4. Agertoft L, Pedersen S. Effects of long-term treatment with an inhaled corticosteroid on growth and pulmonary function in asthmatic children. Respir Med 1994; 88: 373-381.

5. Geddes DM. Inhaled corticosteroids: benefits and risks. Thorax 1992; 47: 404-407.

6. Russell G. Inhaled corticosteroid therapy in children: an assessment of the potential for side effects. Thorax 1994; 49: 1184-1188.

7. Harding SM. The human pharmacology of fluticasone propionate. Respir Med 1990; 80 (Suppl. A): 25-29.

8. Langdon CG, Thompson J. A multicentre study to compare the efficacy and safety of inhaled fluticasone propionate and budesonide via metered-dose inhalers in adults with mild-to-moderate asthma. $\mathrm{Br} J$ Clin Res 1994; 5: 73-84.

9. Langdon CG, Capsey LJ. Fluticasone propionate and budesonide in adult asthmatics: a comparison using drypowder inhaler devices. Br J Clin Res 1994; 5: 85-99.

10. Barnes NC, Marone G, Di Maria GU, Visser S, Utama I, Payne SL. A comparison of fluticasone propionate, $1 \mathrm{mg}$ daily, with beclomethasone dipropionate, $2 \mathrm{mg}$ daily in the treatment of severe asthma. Eur Respir $J$ 1993; 6: 877-885.

11. Ayres JG, Bateman ED, Lundbäck B, Harris TAJ. High dose fluticasone propionate, $1 \mathrm{mg}$ daily, versus fluticasone propionate, $2 \mathrm{mg}$ daily, or budesonide, $1.6 \mathrm{mg}$ daily, in patients with chronic severe asthma. Eur Respir $J$ 1995; 8: 579-586.

12. English AF, Neate MS, Quint DJ, Sareen M. Biological activities of some corticosteroids used in asthma. Am J Respir Crit Care Med 1994; 149: A212.
13. Andersson N, Klint S, Randwall G, Wirén JE. Equipotency of budesonide and fluticasone propionate in the vasoconstriction assay. Am J Respir Crit Care Med 1994; 149: A467.

14. Dahl R, Lundbäck B, Malo JL, et al. A dose-ranging study of fluticasone propionate in adult patients with moderate asthma. Chest 1993; 104: 1352-1358.

15. Fabbri L, Burge PS, Croonenborgh L, et al. Comparison of fluticasone propionate with beclomethasone dipropionate in moderate to severe asthma treated for one year. Thorax 1993; 48: 817-823.

16. Grahnén A, Eckernäs SA, Brundin RM, Ling-Andersson A. An assessment of the systemic activity of single doses of inhaled fluticasone propionate in healthy volunteers. Br J Clin Pharmacol 1994; 38: 521-525.

17. Grove A, Allam C, McFarlane LC, McPhate G, Jackson $\mathrm{CM}$, Lipworth BJ. A comparison of the systemic bioactivity of inhaled budesonide and fluticasone in normal subjects. Br J Clin Pharmacol 1994; 38: 527-532,

18. Clark DJ, Grove A, Cargill RI, Lipworth BJ. Comparative adrenal suppression with inhaled budesonide and fluticasone propionate in adult asthmatic patients. Thorax 1996; 51: 262-266.

19. Lipworth BJ. New perspectives on inhaled drug delivery and systemic bioactivity. Thorax 1995; 50: 105-110.

20. Padfield PL, Teelucksingh S. Inhaled corticosteroids: the endocrinologist's view. Eur Respir Rev 1993; 3: 494500.

21. Law CM, Marchant JL, Honour JW, Preece MA, Warner JO. Nocturnal adrenal suppression in asthmatic children taking inhaled beclomethasone dipropionate. Lancet 1986; i: 942-944.

22. Chervinsky P, Van As A, Bronsky EA, et al. Fluticasone propionate aerosol for the treatment of adults with mild to moderate asthma. J Allergy Clin Immunol 1994; 94: 676-683.

23. Jennings BH, Andersson KE, Johansson SA. Assessment of the systemic effects of inhaled glucocorticosteroids: the influence of blood sampling technique and frequency on plasma cortisol and leucocytes. Eur J Clin Pharmacol 1990; 39: 127-131.

24. Tabachnik E, Zodik Z. Diurnal cortisol secretion during therapy with inhaled beclomethasone dipropionate in children with asthma. J Pediatr 1991; 118: 294-297.

25. Boe J, Bakke P, Rødølen T, Skovlund E, Gulsvik A. High-dose inhaled steroids in asthmatics: moderate efficacy gain and suppression of the hypothalamic-pituitaryadrenal (HPA) axis. Eur Respir J 1994; 7: 2179-2184.

26. Wolthers OD, Pedersen S. Short-term growth during treatment with inhaled fluticasone propionate and beclomethasone dipropionate. Arch Dis Child 1993; 68: 673-676.

27. Ryrfeldt $\AA$, Andersson P, Edsbäcker S, Tönnesson M, Davies D, Pauwels R. Pharmacokinetics and metabolism of budesonide, a selective glucocorticoid. Eur J Respir Dis 1982; 63 (Suppl. 122): 86-95.

28. Thorsson L, Edsbäcker S, Conradson TB. Lung deposition of budesonide from Turbuhaler is twice that from a pressurized metered-dose inhaler pMDI. Eur Respir $J$ 1994; 7: 1839-1844.

29. Mackie AE, Ventresca GP, Moss JA, Bye A. Pharmacokinetics of intravenous fluticasone propionate in healthy subjects. Br J Clin Pharmacol 1995; 40: 198P.

30. Dogterom P, Oosterhuis B, Ebels JT, Jonkman JH. Inhaled fluticasone propionate induces greater cortisol suppression compared to budesonide. A dose response study using pressurized metered-dose inhalers (pMDIs). Eur Respir J 1995; 8 (Suppl. 19): 303s. 